\title{
Dentin Bonding Agents-II Recent Trials
}

\section{Surbhi Kakar, Mridula Goswami, Rohit Nagar}

\section{ABSTRACT}

Most modern adhesive systems are superior to their predecessors, especially in terms of retention that is no longer the main cause of premature clinical failure. Recent adhesives also appear less sensitive to substrate and other clinical covariables. Various recent trials have been conducted on various issues like the antibacterial properties of self-ethching dental adhesive system (which are effective against bacteria that invade through microleakage at the resin dentin interphase), shear bond strength of composite resin to dentin, using newer dentin bonding agents, nanoleakege expression in bonded dentin and next generation bonding agents.

This paper gives the insight to the various recent trials on dental adhesive systems.

How to cite this article: Kakar S, Goswami M, Nagar R. Dentin Bonding Agents-II Recent Trials. World J Dent 2012;3(1): 115-118.

\section{Source of support: Nil}

Conflict of interest: None declared

\section{INTRODUCTION}

In current times, development of new products is occurring at an unprecedented rate. Dentin adhesives are currently available as three-step, two-step and single-step systems, depending on how the three cardinal steps of etching, priming and bonding to tooth substrate are accomplished.

The newer concepts of self-etching primers and adhesives have proven to be good both scientifically and clinically. They reduce the clinical steps, can be placed inexpensively, provide adequate bonding to enamel and dentin, and most importantly, ensure postoperative comfort for patients.

Among proprietary dentin bonding systems (DBS), the products which contain glutaraldehyde or have an acidic property exhibit some antibacterial effects. However, the antibacterial properties shown by these products are only side-effects which are derived from the constituents included to produce superior bonding characteristics, and appear to be unreliable. Inclusion of antibacterial components into DBS has also been attempted using several methods, and the results of in vitro tests indicate that some of the trials seem promising. It is worthy of continuing the attempts to develop DBS which can inhibit invading bacteria after the placement of restoration as well as residual bacteria in the cavity.

Knowledge about hydrolytic degradation is important as hydrolytic degradation of resin-dentin interfaces contribute to the reduction in the bond strength created by dentin adhesives overtime.

This paper reviews the various recent trials on dental adhesive systems.

\section{RECENT TRIALS}

\section{Antibacterial Properties of Self-Etching Dental Adhesive Systems}

In vitro studies have shown that the tooth-restoration interface created when using self-etching adhesive systems do not eliminate microleakage and bacterial penetration, which can lead to secondary caries, the most common reason for dental restoration failure.

Therefore, the antibacterial properties of adhesive materials are important. Studies have shown the antibacterial effect of adhesive materials is due to their low $\mathrm{pH}$ or to specific antibacterial components, such as glutaraldehyde or 12-methacryloyloxydodecylpyridinium bromide (MDPB). Since copolymerization should immobilize MDPB in the adhesive material, adhesives containing MDPB may be effective against bacteria that invade through microleakage.

All of the materials lost their antibacterial properties within 14 days: Adper Prompt 1-Pop after 24 hours. AdheSe and Xeno III within 48 hours and Clearfil Protect Bond after 14 days. It is reasonable to assume that their antibacterial components decomposed at varying rates into the surrounding aging liquid. Current studies hypothesize that not all MDPB molecules copolymerize, and those that do not are able to leach and manifest their antimicrobial properties.

The application of self-etching adhesive materials could contribute toward completely eliminating bacteria or minimizing it during tooth preparation. Since none of the self-etching adhesive systems tested had long-lasting antibacterial properties, they did not provide a solution to the main cause for secondary caries: Bacterial invasion owing to microleakage. ${ }^{1,2}$

\section{An Evaluation and Comparison of Shear Bond Strength of Composite Resin to Dentin, using Newer Dentin Bonding Agents}

Water is a common component in self-etch adhesives for demineralization of dental hard tissues. It has been postulated 
that minimum bond strength of 17 to $20 \mathrm{MPa}$ is needed to resist contraction forces of resin composite materials, for enamel and dentin. Clinical experiences confirm that this bond strength is sufficient for successful retention of resin restoration. All adhesive systems used achieved the optimal bond strength values for both enamel and dentin (except $G$ Bond, which showed a slightly lower value). However, the total etch system prime and bond NT showed better bond strength, as compared to the self-etching adhesives - Clearfil S3, Xeno III, Clearfil Protect Bond and G Bond ${ }^{1}$ (Table 1).

This result was in accordance with Bouillaguet et al, Chuang et al, Kerby et al, who stated that self-etching adhesives have lower bond strength as compared to total etch bonding systems. Senawongse et al, also demonstrated that two self-etching systems, One-up bond and Clearfil SE Bond demonstrated lower bond strength than the total etch system single bond. However, Kiremitci et al concluded that self-etching adhesive systems produced higher bond strength than conventional total etch systems, especially the all-in-one system, which produced the highest bond strength; whereas, Sensi et al stated that self-etch and total etch primer showed comparable dentin bond strength.

According to Hashimato et al self-etch adhesives produced thinner and shorter resin tags than those produced by phosphoric acid-etching and thus, resulted in inferior bond strength as compared to total etch adhesive systems.

Self-etching adhesive systems rely on acidic monomers to simultaneously demineralize and infiltrate enamel and dentin. This acidity must be neutralized by the mineral content of the tooth structure, to allow complete polymerization of the adhesive film. With total etch adhesive, smear layer and dissolved mineral are removed during the rinsing step. Because of some questions about residual acidity and the fact that the smear layer is not removed, the issue of long-term hydrolytic stability of the self-etching adhesive systems still remains unresolved. ${ }^{3,4}$

\section{Aging Affects Two Modes of Nanoleakage Expression in Bonded Dentin}

Nanoleakage was originally used to describe microporous zones beneath or within hybrid layer that permitted traces penetration to occur in the absence of interfacial gaps (Sano et al 1995). It occurs through submicrometer sized spaces within dentin hybrid layers where disparities existed between the depths of demineralization and monomer diffusion (Pioch et al 2001).

Water sorption into resin-dentin interfaces precedes hydrolytic degradation. We hypothesized that these processes are morphologically manifested by the uptake of ammoniacal silver nitrate, which is thought to trace hydrophilic domains and water-filled channels within matrices.

Water sorption is thought to be nonuniform and can be traced by the use of silver nitrate. Human teeth bonded with an experimental filled-adhesive were aged in artificial saliva (experimental) or nonaqueous mineral oil (control). Specimens retrieved for up to a 12-month period were immersed in $50 \mathrm{wt} \%$ ammoniacal silver nitrate and examined by transmission electron microscopy for identification of the changes in their silver uptake. Reticular silver deposits, initially identified within the bulk of hybrid layers in the experimental group, were gradually reduced over time, but were subsequently replaced by similar deposits that were located along the hybrid layer-adhesive interface. Silver uptake in water-binding domains of the adhesive layers increased with aging, resulting in water tree formation (Figs 1 and 2). These water-filled channels may act as potential sites for hydrolytic degradation of resin dentin bonds.

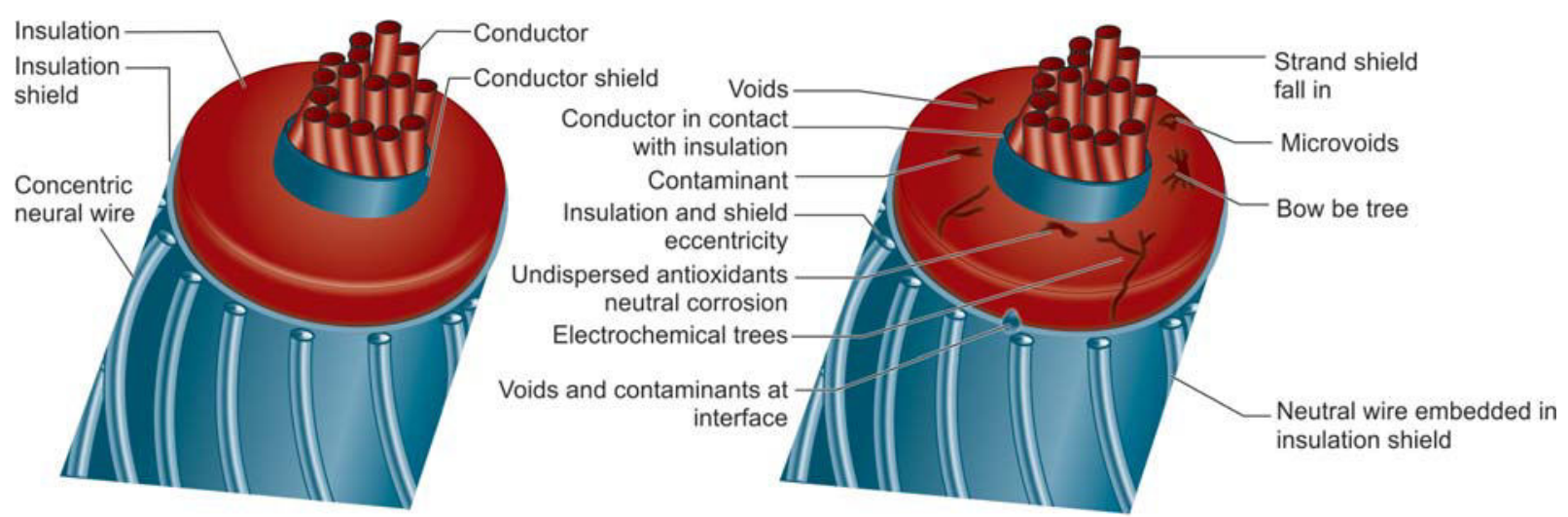

- Submicroscopic tree-like water channels

- Electrochemical oxidation of the hydrophobic polymer into more hydrophilic moieties

- Moisture condensation-self propagation-cable failure

Fig. 1: The term 'water tree' was originated from the tree-like deterioration patterns that were found within the polyethylene insulation of underground electrical cables 

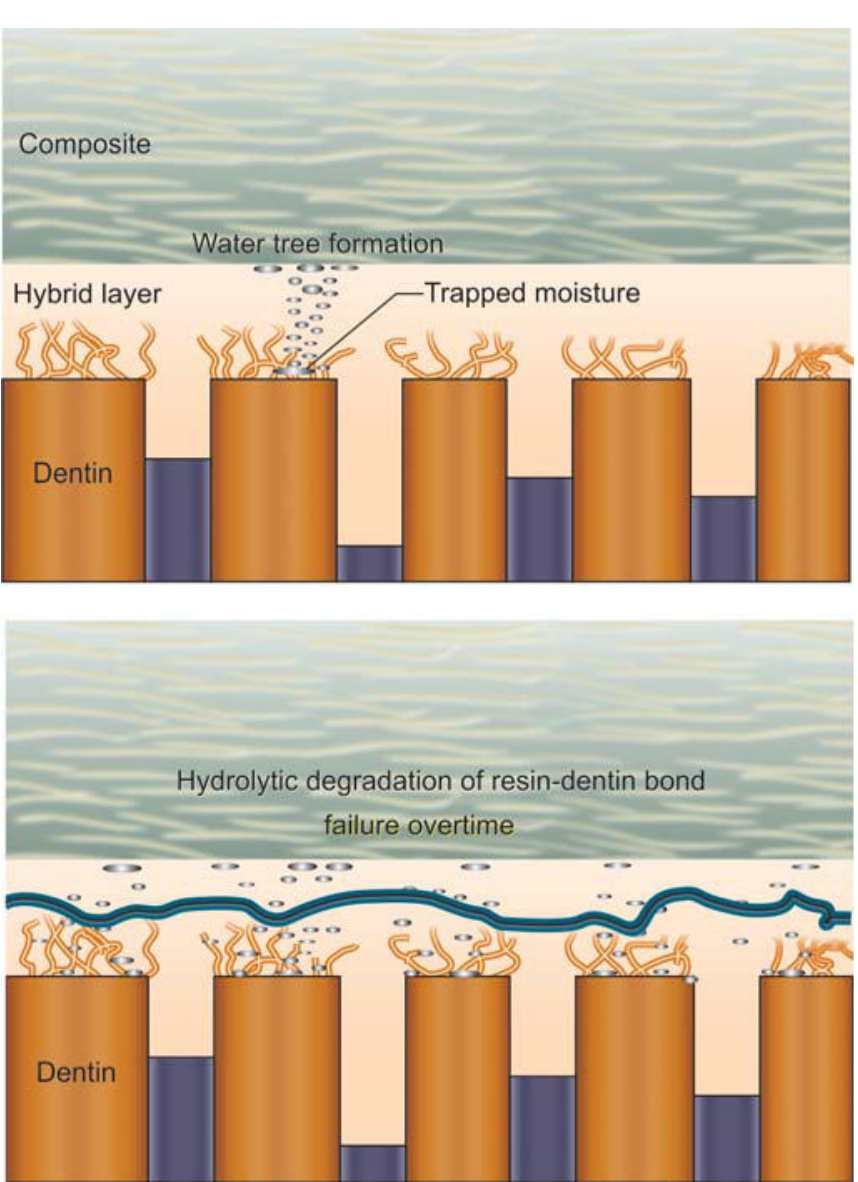

Fig. 2: Water tree effect

Hydrolytic degradation of resin-dentin interfaces contributes to the reduction in bond strengths created by dentin adhesives overtime (Watanabe and Nakabayashi 1993; Gwinnett and Yu 1995: Burrow et al 1996; Shono et al 1999; Armstrong et al 2001).

Hydrolytic degradation can not occur in the absence of water uptake in bonded interfaces. Water sorption is enhanced by the presence of hydrophilic and ionic resin

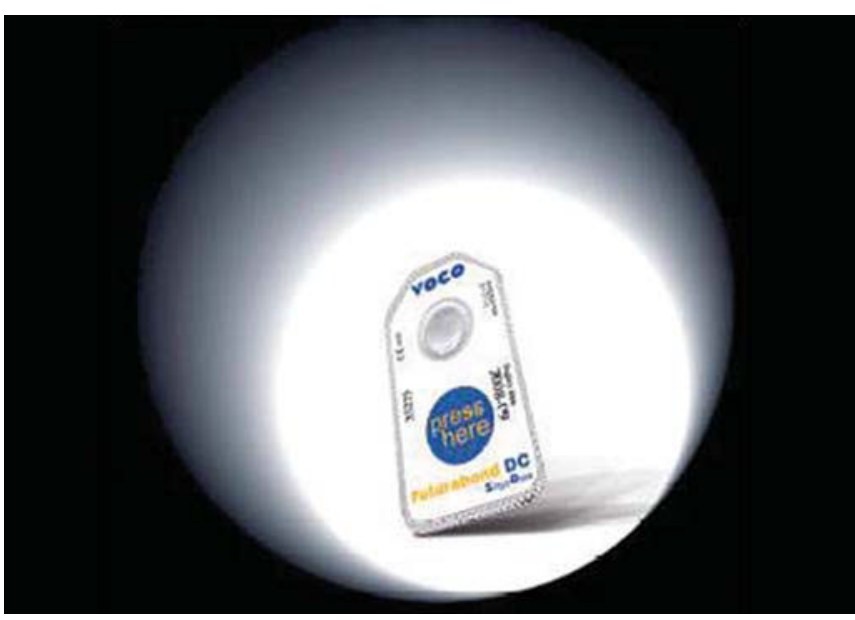

Fig. 3: Futura bond DC

monomers (Burrow et al 1999; Tanaka et al 1999), which in turn facilitates ion movement within a polymerized resin matrix (Antonucci et al 1996). To date, the morphological correlates of the time-dependent process of water sorption in resin dentin interfaces have not been elucidated. Ammoniacal silver nitrate has been recently used to trace water-filled regions and/or hydrophilic polymer domains within hybrid layers and the adhesive layers in resin-bonded dentin and enamel (Tay and Pashley 2003). These results revealed two different modes of silver tracer deposition patterns (Tay et al 2002). We hypothesize that water sorption and, subsequently, hydrolytic degradation may be reflected by the changes in uptake of ammoniacal silver nitrate within resin-dentin interfaces. ${ }^{5-7}$

\section{IS THIS THE FIRST 8TH-GENERATION BOND?}

\section{Futura Bond DC Dual-Cured}

- It is dual-cured and works with all light-, self- or dualcured resins

Table 1: Composition of few single-step, self-etch adhesives

\begin{tabular}{|c|c|c|c|}
\hline Self-etch adhesive & Manufacturer & Type & Composition \\
\hline Prompt I-Pop & 3M-ESPE, Seefeld, Germany & Unfilled & $\begin{array}{l}\text { Water', stabilizer, parabenes; methacrylated } \\
\text { phosphoric acid esters; Auoride complex; } \\
\text { photoinitiator (BAPO) }\end{array}$ \\
\hline Etch and prime 3.0 & Dentsply, Degussa AGHanau, Germany & Unfilled & $\begin{array}{l}\text { Universal: Water', ethanol, HEMA, } \\
\text { stabilizers, Catalyst: Pyrophosphate, HEMA, } \\
\text { stabilizers, photoinitiator }\end{array}$ \\
\hline $\begin{array}{l}\text { One-up } \\
\text { Bond F }\end{array}$ & $\begin{array}{l}\text { Tokuyama Corp, } \\
\text { Tokyo, Japan }\end{array}$ & Filled & $\begin{array}{l}\text { Water', MMA, HEMA; coumarin dye; } \\
\text { methacryloyloxyalkyl acid phosphate; } \\
\text { methacryloxyundecane dicarboxylic acid; } \\
\text { multifunctional methacrylic monomer; } \\
\text { fluoroaluminosilicate glass; photoinitiator } \\
\text { (aryl borate catalyst). }\end{array}$ \\
\hline $\begin{array}{l}\text { Reactmer } \\
\text { Bond }\end{array}$ & Shofu Inc, Kyoto, Japan & Filled & $\begin{array}{l}\text { Reactmer Bond A: Water', acetone, F-PRG } \\
\text { fillers, FASG fillers, initiators (TMBA, } \\
\text { p-TSNa). Reactmer Bond B: 4-AET, 4-AETA, } \\
\text { HEMA, UDMA, photoinitiator }\end{array}$ \\
\hline
\end{tabular}

Abbreviations: 4-AET, 4-acryloxyethyltrimellitic acid; 4-AETA, 4-acryloxyethyltrimellitic anhydride; BAPO, bisocyl phosphine oxide; F-PRG, full reaction-type prereacted glass-ionomer filler; FASG, fluoroaluminosilicate glass; HEMA, 2-hydroxylethyl methacrylate; MMA methyl methocrylate; $p$-TSNa, p-toluenesulfinic acid sodium salt; TMBA, trimethyl barbituric acid; UDMA, urethane dimethacrylate 
- It works in a self-cured mode without any light: Great for postcementation

- It takes only 35 seconds from start to finish

- It needs only one coat (Fig. 3) ${ }^{3}$

- It comes in unit dose providing the freshest chemistry each time

- It does not need to be refrigerated or shaken before use

- No sensitivity

- Over $30 \mathrm{MPa}$ bond strength to dentin and enamel. ${ }^{8}$

\section{CONCLUSION}

The clinical performance of present day adhesives has significantly improved, allowing adhesive restorations to be placed with a high predictable level of clinical success. Most of new products are improvements over there predecessor therefore it is indispensible for the professionals to know about them in order to select and use them correctly.

\section{REFERENCES}

1. Osnat Feuerstein, Shlomo Matalon. Antibacterial properties of self-etching dental adhesive systems. JADA, 138;349-53.

2. L Sebnem Türkün, Mustfa Ates, et al. Antibacterial activity of two adhesive systems using various microbiological methods. J Adhes Dent 2005;7:315-20.

3. Mitra N Hegdi. An evaluation and comparison of shear bond strength of composite resin to dentin using newer dentin bonding agents. J Conserv Dent 2008;11:71-75.

4. Claus-Peter Ernst, Marcus Holzmeier, et al. In vitro sheer bond strength of self-etching adhesives in comparison to 4th and 5th generation adhesives. J Adhes Dent 2004;6:293-99.
5. Tay FR, Pashly DH. Aging affects two modes of nanoleakage expression in bonded dentin. J Dent Rest 2002;7:472-76.

6. Ulrich Salz, Jörg Zimmermann, et al. Hydrolytic stability of self-etching adhesive system. J Adhes Dent 2005;7:107-16.

7. Deliperi S, Bardwell DN, et al. Restoration interface microleakage using one total-etch and three self-etch adhesives. Operative Dentistry 2007;32-2:179-84.

8. VOCO America, Inc.<newsletter@dentalcompare.com>

\section{ABOUT THE AUTHORS}

\section{Surbhi Kakar}

Senior Resident, Department of Endodontics, Maulana Azad Institute of Dental Sciences, New Delhi, India

\section{Mridula Goswami}

Professor, Department of Pediatric Dentistry, Maulana Azad Institute of Dental Sciences, New Delhi, India

\section{Rohit Nagar}

Assistant Professor, Department of Conservative Dentistry and Endodontics, Kalka Dental College, Meerut, Uttar Pradesh, India

\section{CORRESPONDING AUTHOR}

Surbhi Kakar, Senior Resident, Department of Endodontics, 106, Nilgiri Apartments, Alaknanda, New Delhi-110019, India Phone: 9871603152, 011-42143096, Fax: 011-26030713 e-mail:kakarsurbhi@gmail.com 